\title{
Hip contact forces and moments at total hip joint prosthesis during walking using AMTI force 5 hip simulator
}

\author{
Dr. Sadiq J. Abbas ${ }^{1}$, Umaima R. Khairy ${ }^{2}$ \\ ${ }^{l}$ Biomedical Engineering Department, College of Engineering, Al-Nahrain University \\ ${ }^{2}$ Biomedical Engineering Department, College of Engineering, Al-Nahrain University
}

\begin{abstract}
In this study, forces and moments at six twenty eight millimeters femoral heads hip joint implants were measured during walking using AMTI force 5 hip simulator depending upon the curves of the angles of the angular motion of the hip joint in three axes (abduction\abduction, flexionlextension and internaAexternal rotation) and the force that is vertically applied on the hip joint during one gait cycle taken from the ISO standard (14242_I 2014). Four of the tested implants had cross-linked polyethylene acetabular cup and two of them had ultra-high molecular weight polyethylene acetabular cup, and all of the tested implants had femoral head made of cobalt-chromium-molybdenum alloy. The first peak of the resultant force ranges between 285-327 $\% B W$ at about $15 \%$ of the gait cycle. The second peak ranges between 292-319\%BW at about $52 \%$ of the gait cycle. These peaks are generally higher than the usual peaks because the muscle forces that pull the joint components close together and lessen the forces applied at the joint do not exist in the simulation of the research testing machine, the testing result do not include the muscles' forces applied at the implant when it is implanted in the human body.
\end{abstract}

Keywords: AMTI force 5, Biomechanics, Hip joint prosthesis, Hip simulator.

Date of Submission: 21 December 2016

$\longrightarrow$

Date of Accepted: 13 January 2017

\section{INTRODUCTION}

Measuring forces and moments applied at artificial joints during daily living activities has been a challenge for the last decades especially when accurate such measurements could be of a huge importance in determining the design characteristics of artificial joints such as the shape, dimensions and manufacturing materials. As well studying the degree of wear, friction, corrosion and lubrication at artificial implants while they are implanted in the human body was a matter of concern. Hip joint implant was the most implant type involved in research directed for such a topic. Most of these research used the telemetry artificial hip joints as their devices to take such measurements, but differences between subjects, joint types and measuring and analyzing systems are all limitations from considering their results as general measurements that could be depend on in all cases.

In this paper forces and moments at hip joint implants during walking were measured using AMTI force 5 hip simulator depending upon the ISO standard (14242_1\2014) which provides curves of the angles of the angular motion of the hip joint in three axes (abductionlabduction, flexionlextension and internallexternal rotation) and the force that is vertically applied on the hip joint during one gait cycle.

\subsection{Forces at Hip joint}

The forces applied at the joint can be generalized to be the gravitational force, the inertial force and the reaction force. The gravitational force is the force that is constantly present. It acts at the center of mass of the body segment. Though the gravitational force is constant, it produces a moment that depends on the location of the segment's center of mass and its center of rotation; thus, the gravitational moments change constantly as the body configuration changes. The inertial force is the force that opposite the muscle force initiates from the body segments' inertial properties and is therefore called inertial force, It is proportional but oppositely directed to the acceleration of the segment. The reaction force is the force applied by the walking flat against the foot. This force is a reaction to the developed forces by the moving body rather than from the flat itself. [1]

\subsection{Moments about Hip Joint}

The following data and the produced observations show the variations in the moments at different positions of the joint. Hip Flexors: Maximal hip moment measured during flexion shows that the moment decreases as flexion increases. [2]

Hip Extensors: The maximal moment developed during extension is at around $70^{\circ}$ of flexion and decreases progressively. [2] 
Hip contact forces and moments at total hip joint prosthesis during walking using AMTI force 5 hip ..

Hip Abductors: There is an almost linear decrease in the moment as the abduction of the hip increased. [3]

\subsection{Artificial Hip Joint Design Requirements}

The materials used to manufacture the artificial hip joint components, the femoral head and the acetabular cup, must be highly biocompatible, bear low friction but have high wear resistance, have sufficient mechanical strength properties such as Young's modulus, fracture toughness and fatigue life and chemically stable. [4] The joint design must meet the range of motion requirements that are present in the normal joint, some movements like squatting and sitting cross legged requires the maximum range of motion of the normal hip joint. Also the joint design must undertake the stresses that are applied at normal joint, vertical load on the femoral ball creates a tensile stress on the lateral side and a compressive stress on the medial side of a hip stem. While anterior load produces shear stresses at the prosthesis-cement-bone and prosthesis-bone interfaces [4].

\subsection{Joint simulators}

When a new design of hip joint is produced, it must be examined on a simulator [4]. Hip simulators must have the following specifications to have the ability to perform the optimum simulator functions [5]:

1. The ability to make the joint move in all three axes.

2. The ability to move the implant with the maximum range of movement of the normal joint.

3. Applying maximum and minimum values of forces which depend upon body weight and walking speed.

4. The ability to move the implant with various speeds.

5. Having implant holders that can receive the commercially available implant components with as easy ways as possible.

6. Having a lubricant container that surrounds the implant and a temperature gauge for the lubricant.

7. The ability to measure friction, moment, compressive forces.

\subsection{Force 5 Simulator By AMTI company (Advanced Mechanical Technology, Inc)}

AMTI force 5 simulator is a single station joint simulator, with movement about three axes (Flexion/Extension, Abduction/Adduction, Internal/External Rotation), anatomically positioned the head with the cup, with four degree of freedom (load and three motions). Four servo-hydraulic actuators run the base station of the machine; with these actuators the machine can perform many different independent or combined motions. The control system is composed of a computer and an embedded digital signal processor located in the machine. The computer provides the user interface, and the DSP provides the control on time critical functions and data acquisition. The computer communicates with the DSP through an Ethernet cable which provides a reliable exchange of commands and data between the two sybsystems. The computer is supplied with a software package named AMTI NetControl which provides the user interface to the machine so the real time data is displayed through 39 types of displayed data could be driven from the machine sensors, these outputs could be distributed among eight channels according to the user need, and these displayed data could be saved to files. The machine is provided with two actuators, upper and lower actuators, by which the joint components are set in the machine. The upper actuator responsible for the horizontal movement and the lower one responsible for the vertical movement and they both perform rotational movement according to the limits of the machine. [6]

\subsection{Hip joint implant specimens}

\section{Experimental work}

Six hip joint implant specimens were tested. Table 1 shows all the details of the specimens' materials and sizes. Figures 1 and 2 show the tested hip joint implants.

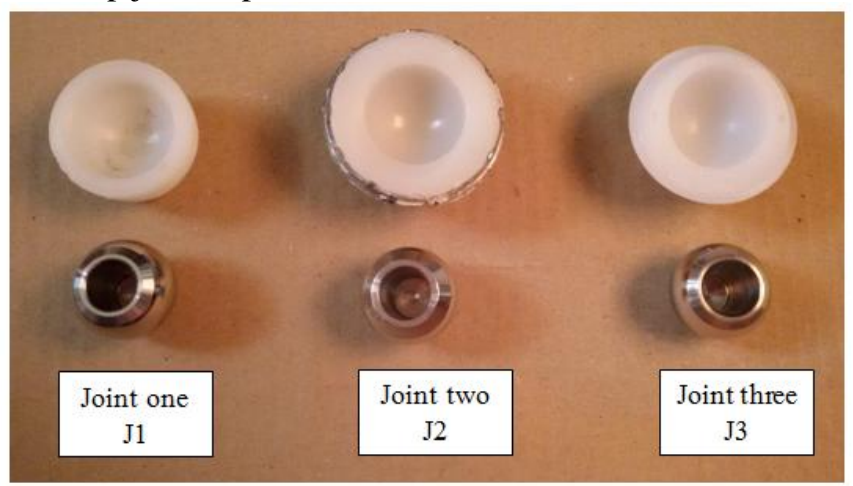

Figure 1 tested hip joint implants numbers one, two and three. 


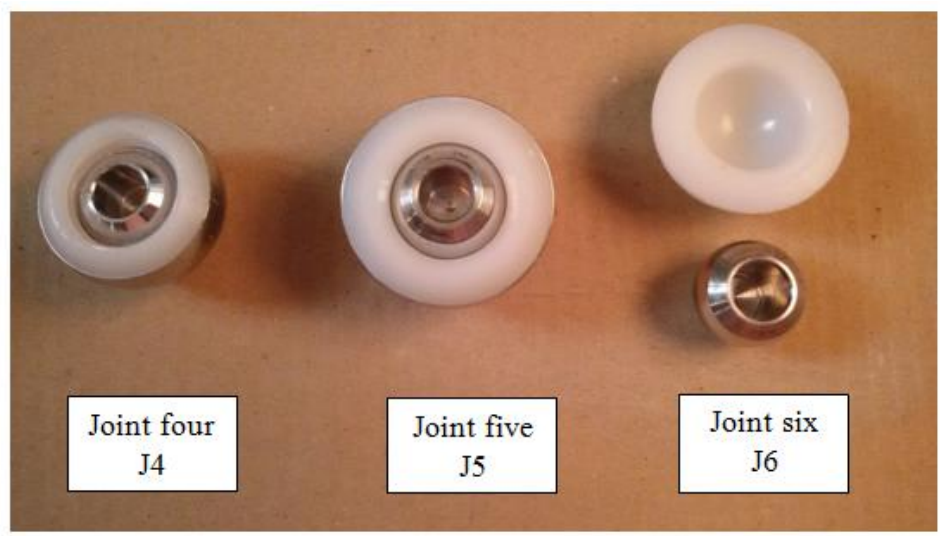

Figure 2 tested hip joint implants numbers four, five and six.

Table 1 Tested specimens' details.

\begin{tabular}{|l|l|l|l|l|l|l|}
\hline $\begin{array}{l}\text { Specimen's } \\
\text { number }\end{array}$ & 1 & 2 & 3 & 4 & 5 & 6 \\
\hline $\begin{array}{l}\text { Acetabular cup } \\
\text { material }\end{array}$ & $\begin{array}{l}\text { Cross linked } \\
\text { polyethylene }\end{array}$ & $\begin{array}{l}\text { Cross linked } \\
\text { polyethylene }\end{array}$ & UHMWPE & UHMWPE & UHMWPE & UHMWPE \\
\hline $\begin{array}{l}\text { Femoral head } \\
\text { material }\end{array}$ & Co-Cr-Mo alloy & Co-Cr-Mo alloy & $\begin{array}{l}\text { Co-Cr-Mo } \\
\text { alloy }\end{array}$ & Co-Cr-Mo alloy & $\begin{array}{l}\text { Co-Cr-Mo } \\
\text { alloy }\end{array}$ & $\begin{array}{l}\text { Co-Cr-Mo } \\
\text { alloy }\end{array}$ \\
\hline $\begin{array}{l}\text { Femoral head } \\
\text { diameter }\end{array}$ & $28 \mathrm{~mm}$ & $28 \mathrm{~mm}$ & $28 \mathrm{~mm}$ & $28 \mathrm{~mm}$ & $28 \mathrm{~mm}$ \\
\hline
\end{tabular}

UHMWPE: Ultra high molecular weight polyethylene.

Co-Cr-Mo: cobalt-chromium-molybdenum.

\subsection{Setting the hip joint implant}

The head of the hip joint implant was set to its holder which was attached to a sensor cup and the sensor cup was attached to the lower actuator. The cup of the hip joint implant was set into its holder which was anchored to the drive shoe which was fixed to the upper actuator as in figure 3 . The machine was calibrated before being used in the research tests.

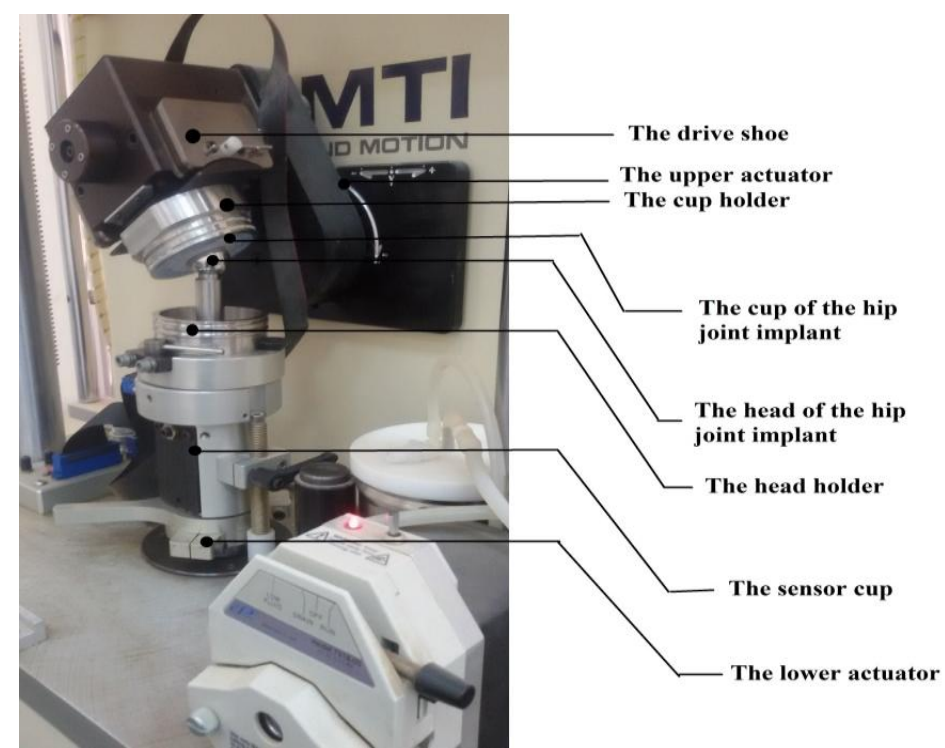

Figure 3 The hip joint components after setting in the machine.

In order to set the head in its place, a head holder must be designed to fit it. According to the design of the machine and its manual [6] a holder was manufactured from (Stainless Steel 316). The manual states that the range of the distance between the centerline of the head and the lower surface of the head holder is $(4.1-6.3) \mathrm{cm}$ and according to the provided samples. So a fixed distance was chosen for all the heads' holders which is $4 \mathrm{~cm}$ since all the specimens are of $28 \mathrm{~mm}$ diameter. Figure 4 




Figure 4 The specimen's head holder.

The socket of the joint was fixed so that the socket was placed in the right position of the half ball socket holder taking into account matching the center of the socket and the center of the holder. Figure 5

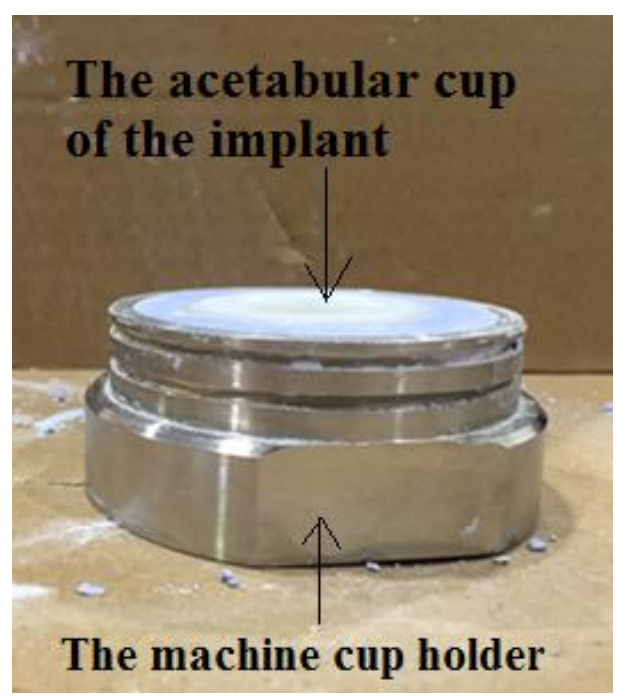

Figure 5 matching the center of the cup with that of the holder.

High strength dental stone was used as a fixing material to set the cup of the joint into its holder. High strength dental stone is a material used by dentists to fabricate crowns and in the use of bridge techniques. Chemically, it is basically gypsum (Calcium phosphate dihydrate) $\mathrm{CaSO}_{4} \cdot 2 \mathrm{H}_{2} \mathrm{O}$ heated to evaporate water producing Calcium phosphate hemihydrate $\mathrm{CaSO}_{4} \cdot 12 \mathrm{H}_{2} \mathrm{O}$ which is type IV gypsum or high strength dental stone (Calcium phosphate hemihydrate).

To set the cup of the joint the following steps were followed:

1. An amount of dental stone was mixed with water until it becomes creamy structured, figure 6 .

2. The creamy structured dental stone was poured in the cup holder, and then the cup was put in the right position of the holder.

3. The stone was waited to be dried (drying requires half to one hour)

4. Then simply the holder was put in its place in the machine.

5. To unfix the cup, the stone was hammered with a hammer and a metal stick until it becomes powdery fragments (this process needs about one hour). 


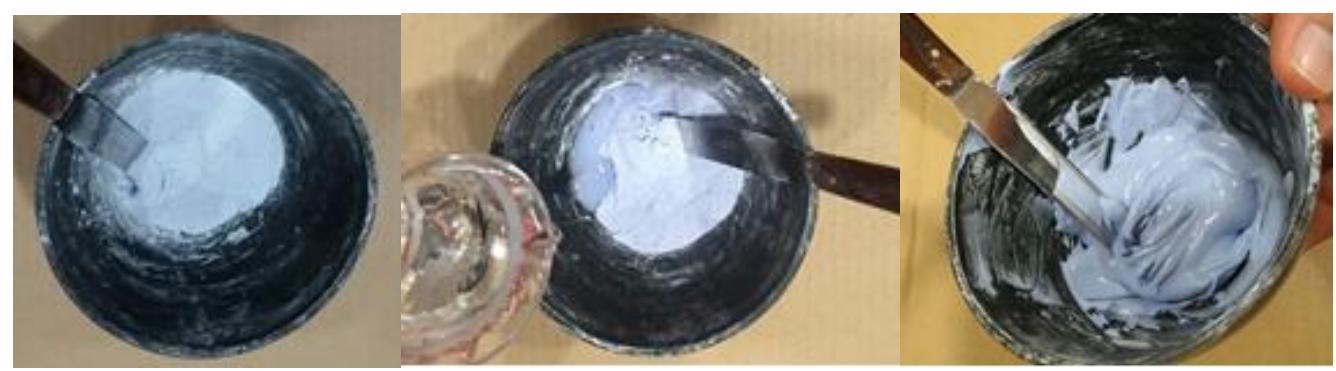

(a)

(b)

(c)

Figure 6 Mixing dental stone with water. (a) an amount of dental stone powder prepared to be mixed, (b) mixing dental stone with water, (c) the creamy structured dental stone.

\subsection{Programming the Input Curves (Forces and Angles)}

The machine requires input curves representing the force that would be applied on the tested joint and the angles by which the joint would move in three directions. These inputs are determined according to the movement through which the joint is desired to be tested (walking). The third edition (14242_1\2014) ISO standard provides curves of the angles of the angular motion of the hip joint in three axes (abductionlabduction, flexionlextension and internallexternal rotation) and the force that is applied on the hip joint both are during a whole one gait cycle. These standard curves were programmed and transformed into numbered data to be entered as the walking inputs to the machine, these numbered data are illustrated as curves as in figures 7 and 8 .

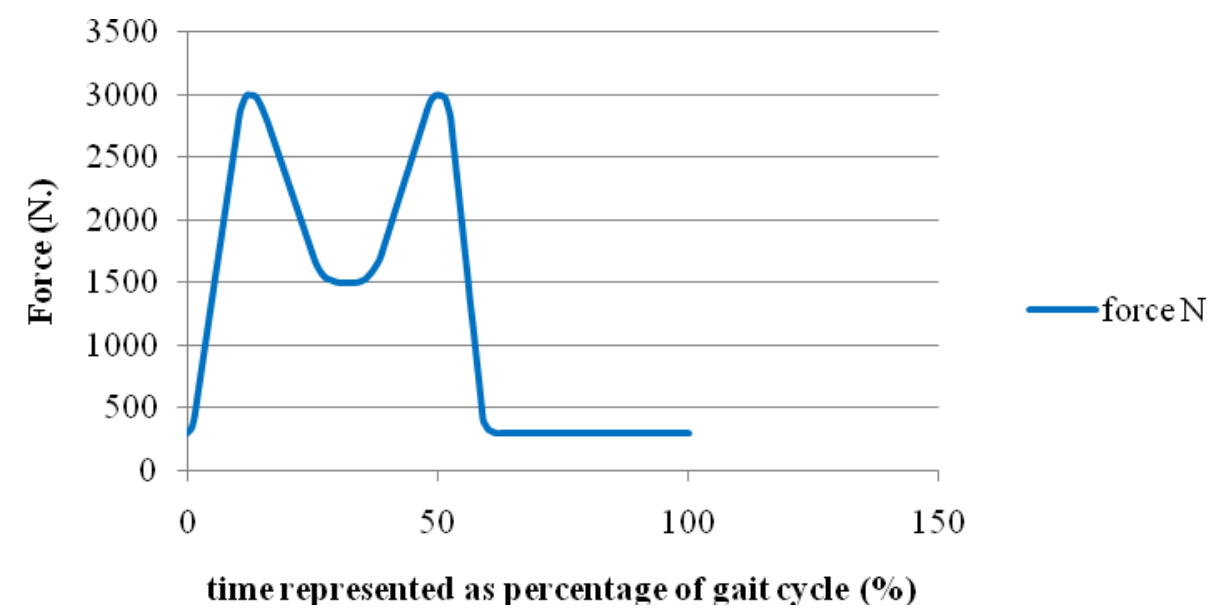

Figure 7 Force applied on hip joint during one gait cycle after the curves had been transformed into numbered data and redrawn.

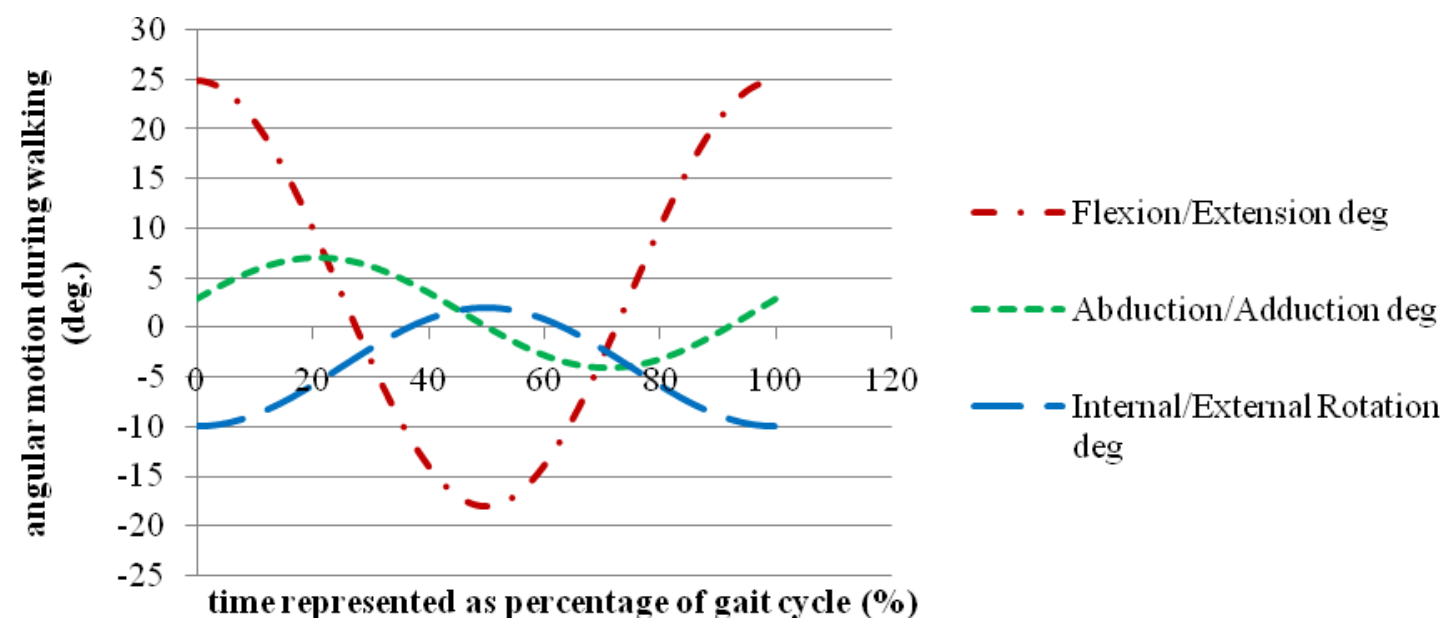

Figure 8 Angular motion of the hip joint in three axes after programming and transforming into numbered data represented as curves. 


\section{Results}

Each hip joint implant was tested using the simulator applying the input force and angles to get the following curves. The curves represent the forces and moments at the joint in three directions during one walking gait cycle. Figure 9, 10and 11 represent the forces in newton $(\mathrm{N})$ and figures 13, 14 and 15 represent the moments in newton.meter (N.m).

As for the directions, $\mathrm{x}$ is in the antero-posterior direction, $\mathrm{y}$ is in the medio-lateral direction and $\mathrm{z}$ is in the vertical direction with respect to the joint.

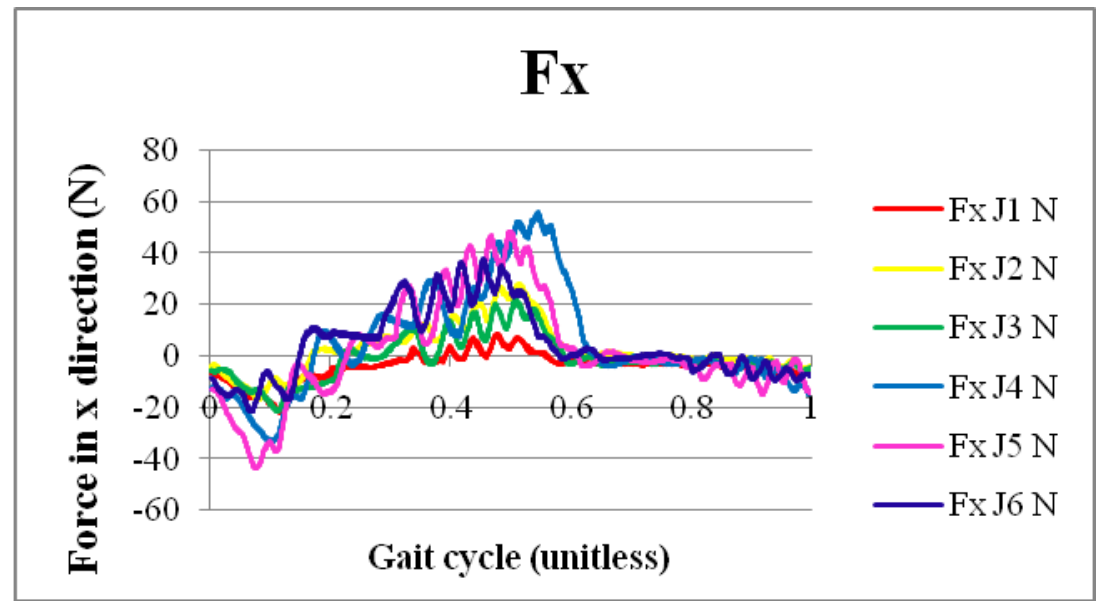

Figure 9 Forces at the tested joints in the $\mathrm{x}$ antero-posterior direction during one gait cycle measured in $\mathrm{N}$.

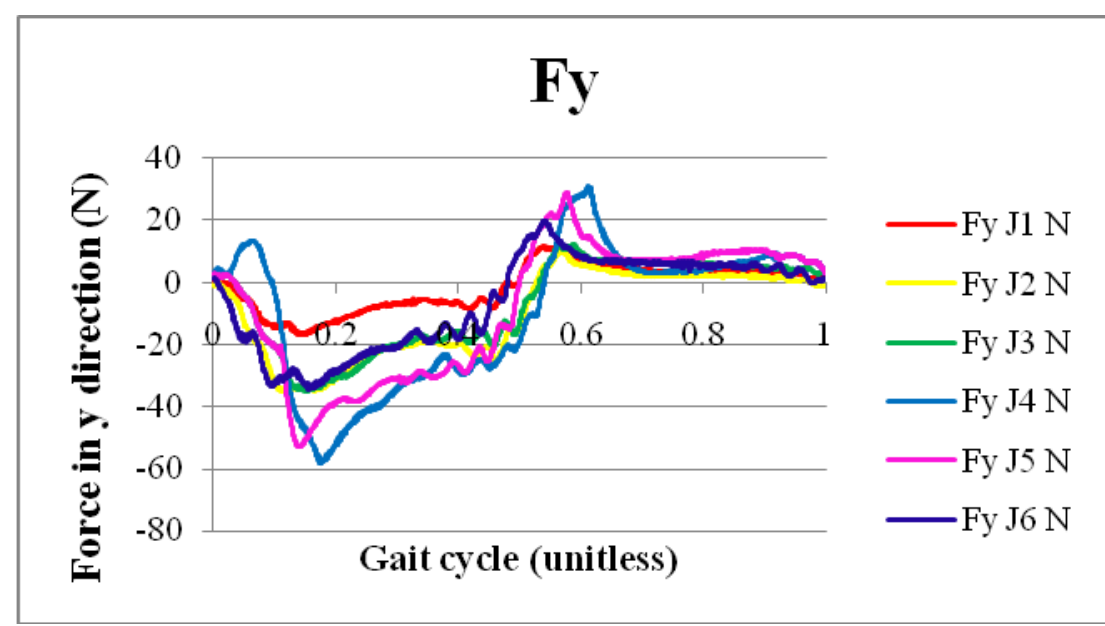

Figure 10 Forces at the tested joints in the y medio-lateral direction during one gait cycle measured in $\mathrm{N}$.

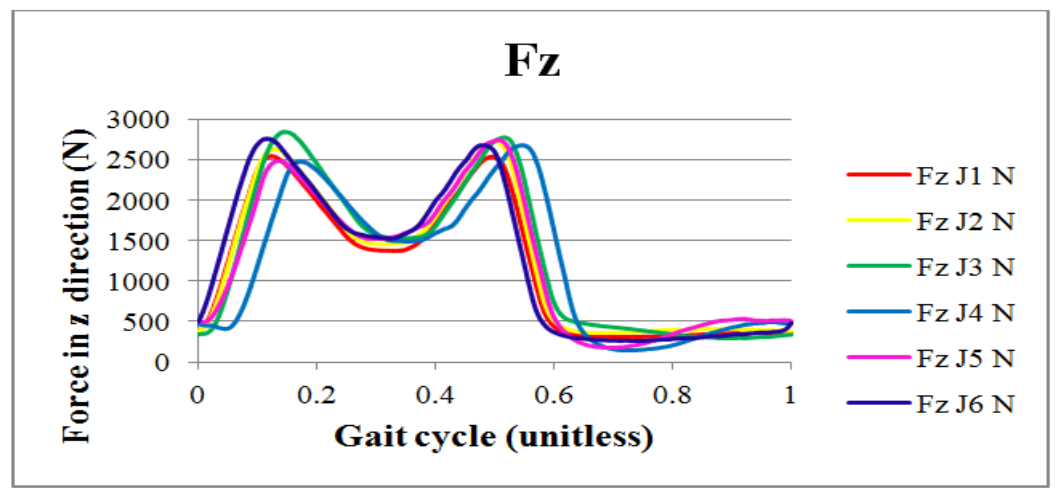

Figure 11 Forces at the tested joints in the $\mathrm{z}$ vertical direction during one gait cycle measured in $\mathrm{N}$.

As it is obvious that the magnitudes of the forces in the $\mathrm{x}$ and $\mathrm{y}$ directions are negligible compared to the force in the $\mathrm{z}$ direction as in figure 12, so it is possible to assume $\mathrm{Fz}$ is the same as the resultant force applied at the hip joint. 




Figure 12 Forces at the tested joints in the $\mathrm{x}$ antero-posterior (red), $\mathrm{y}$ medio-lateral (green) and $\mathrm{z}$ vertical (blue) directions measured in $\mathrm{N}$.

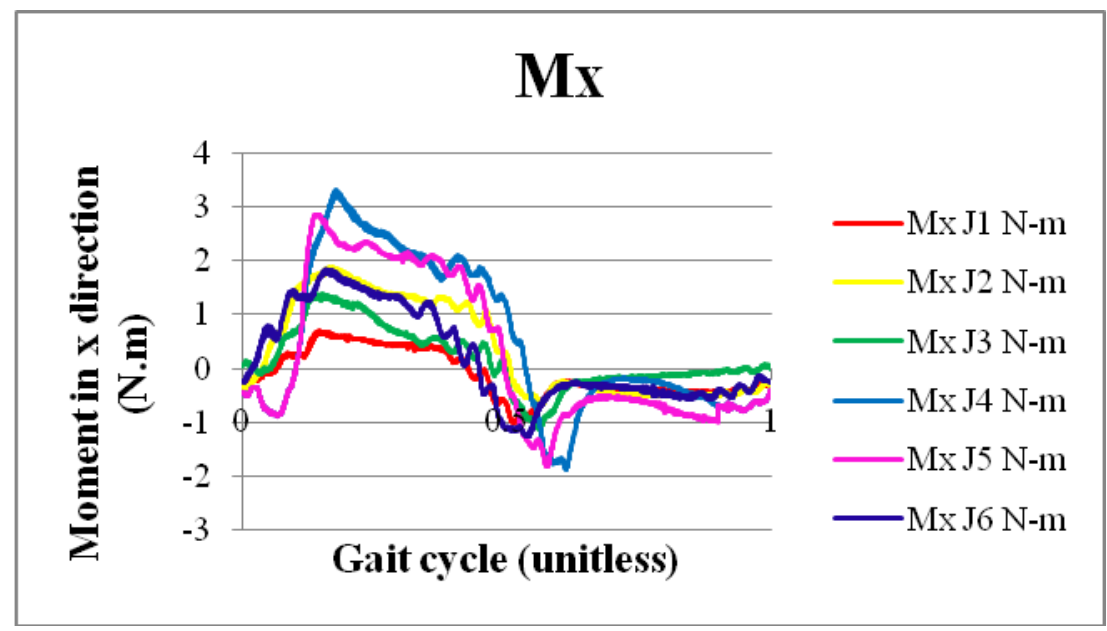

Figure 13 moments at the tested joints in the $\mathrm{x}$ antero-posterior direction measured in N.m.

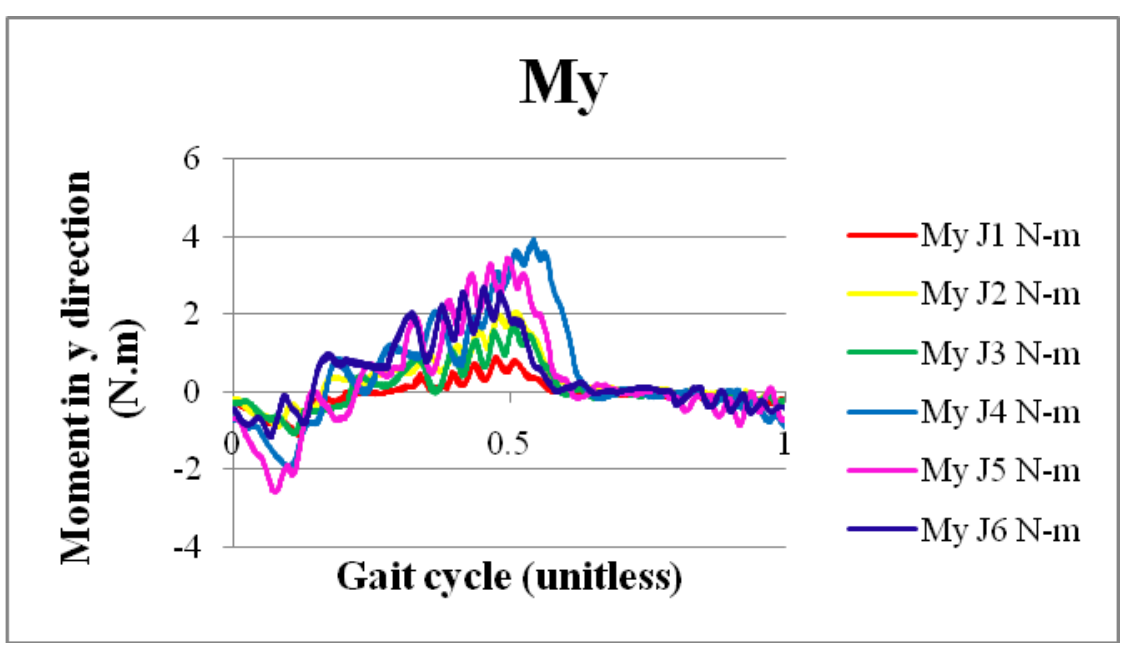

Figure 14 moments at the tested joints in the y medio-lateral direction measured in N.m. 


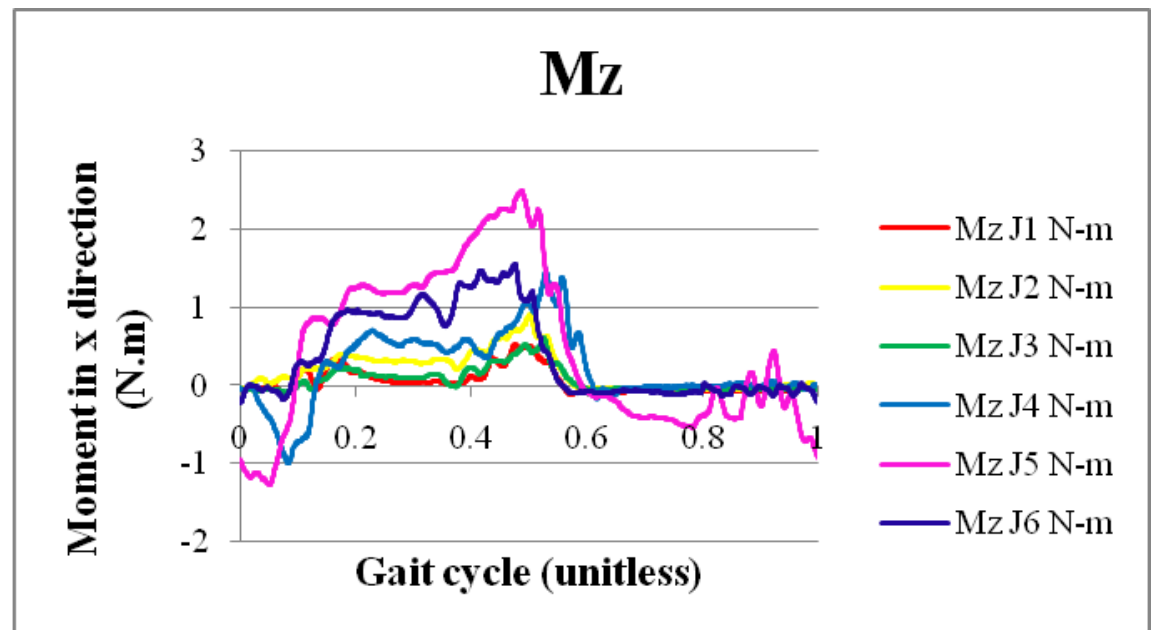

Figure 15 moments at the tested joints in the $\mathrm{z}$ vertical direction measured in N.m.

According to the anthropometric reference data for children and adults from the vital and health statistics in 2016 [7], the standard adult male's body weight is $88.8 \mathrm{Kg}$. So the results of forces and moments in \%BW and in $\% \mathrm{BW}$-m respectively are shown in figures $16,17,18,19,20$ and 21.



Figure 16 Forces at the tested joints in the $\mathrm{x}$ antero-posterior direction during one gait cycle measured in $\% \mathrm{BW}$.

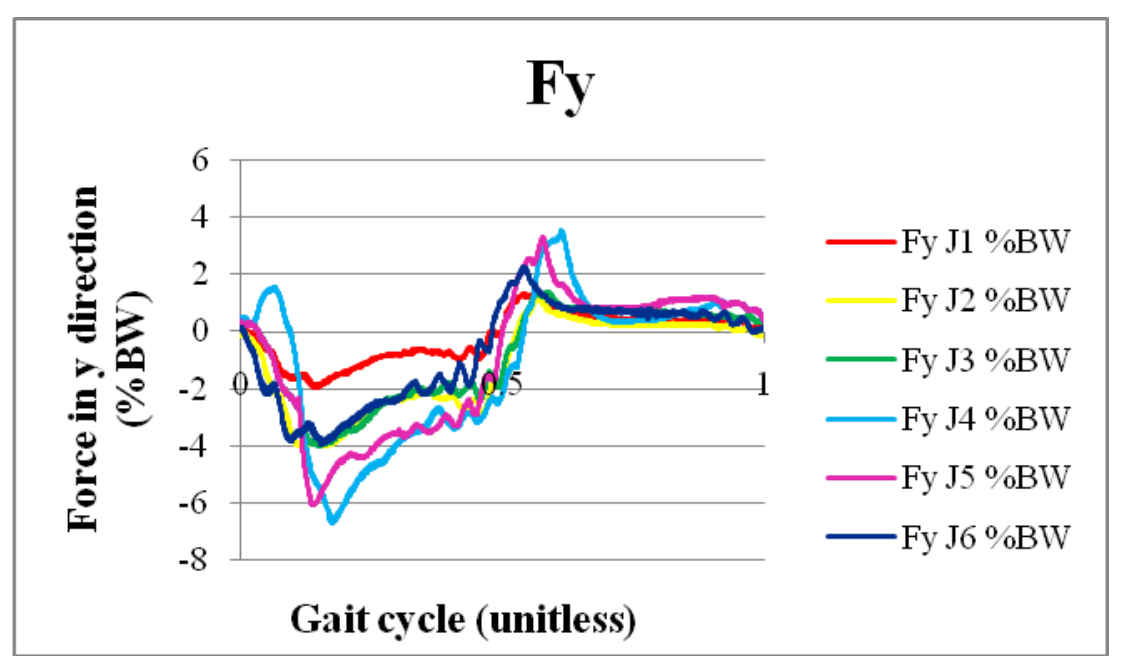

Figure 17 Forces at the tested joints in the y medio-lateral direction during one gait cycle measured in $\% \mathrm{BW}$. 


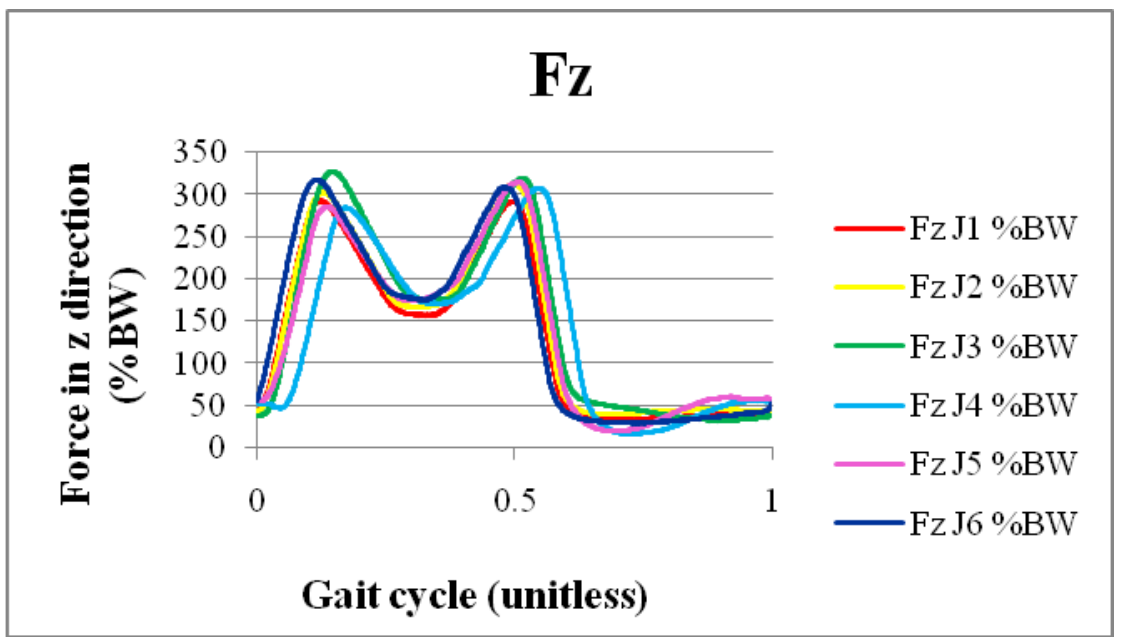

Figure 18 Forces at the tested joints in the $\mathrm{z}$ vertical direction during one gait cycle measured in \% $\mathrm{BW}$.

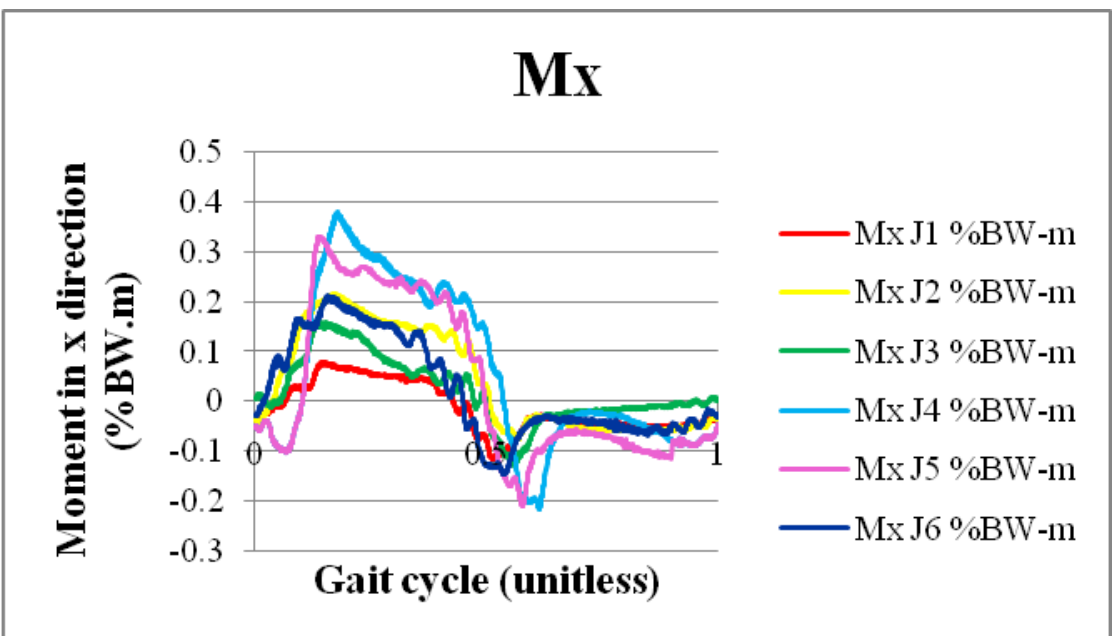

Figure 19 moments at the tested joints in the $\mathrm{x}$ antero-posterior direction measured in \%BW.m.

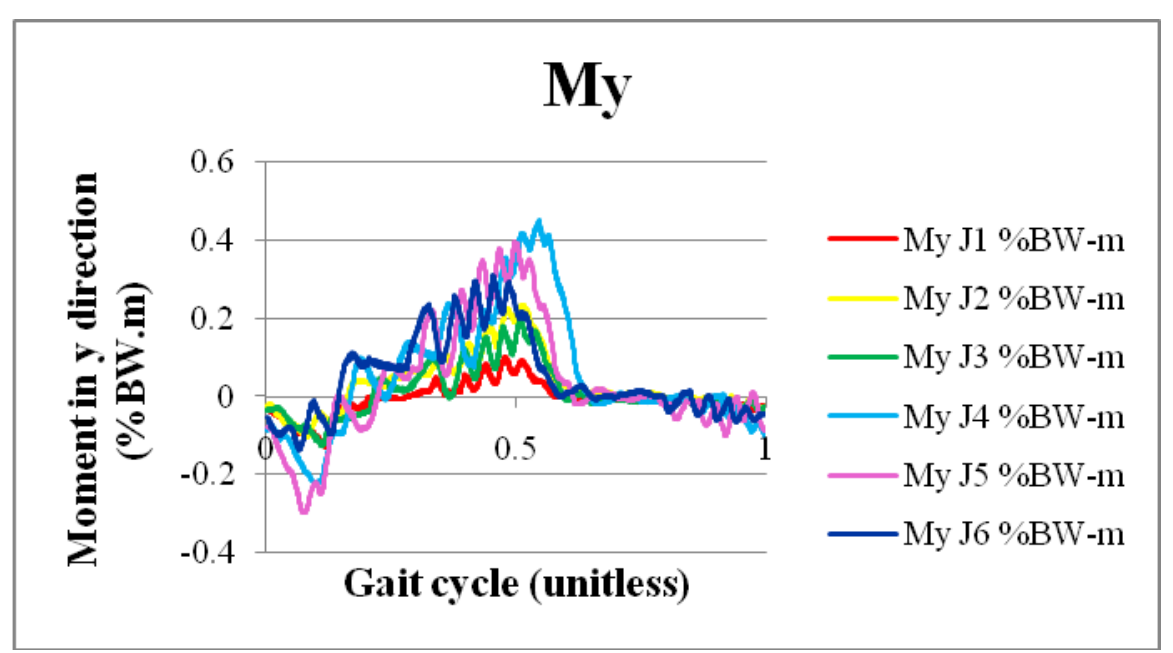

Figure 20 moments at the tested joints in the y medio-lateral direction measured in \%BW.m. 


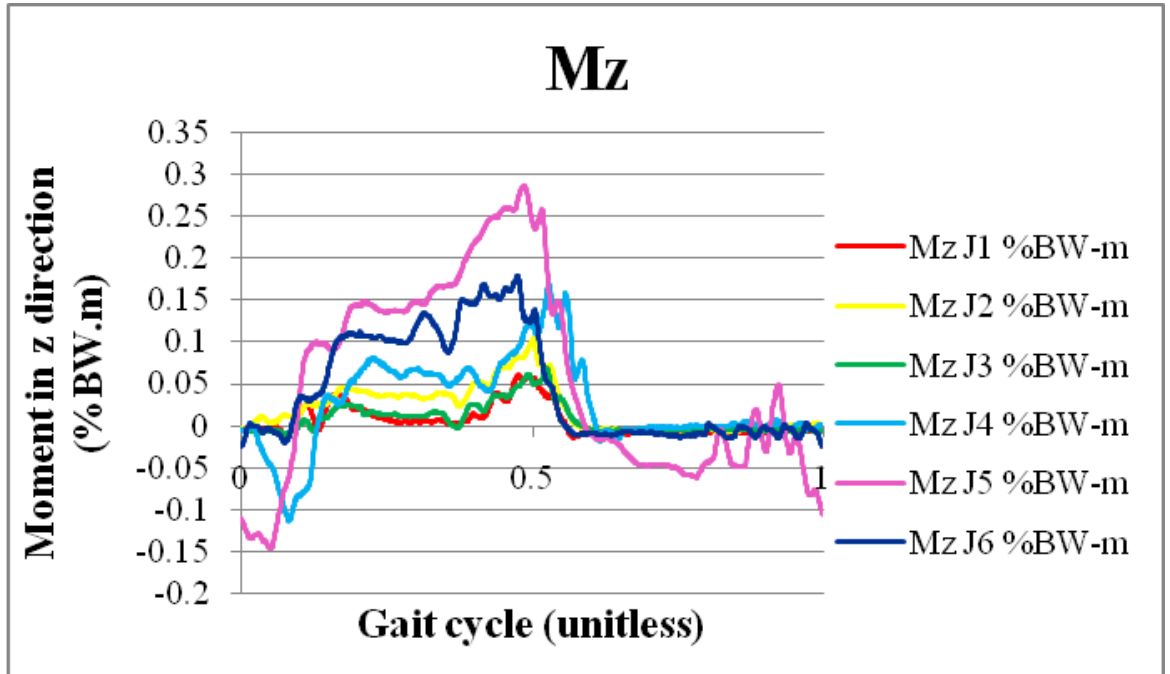

Figure 21 moments at the tested joints in the $\mathrm{z}$ vertical direction measured in \%BW.m.

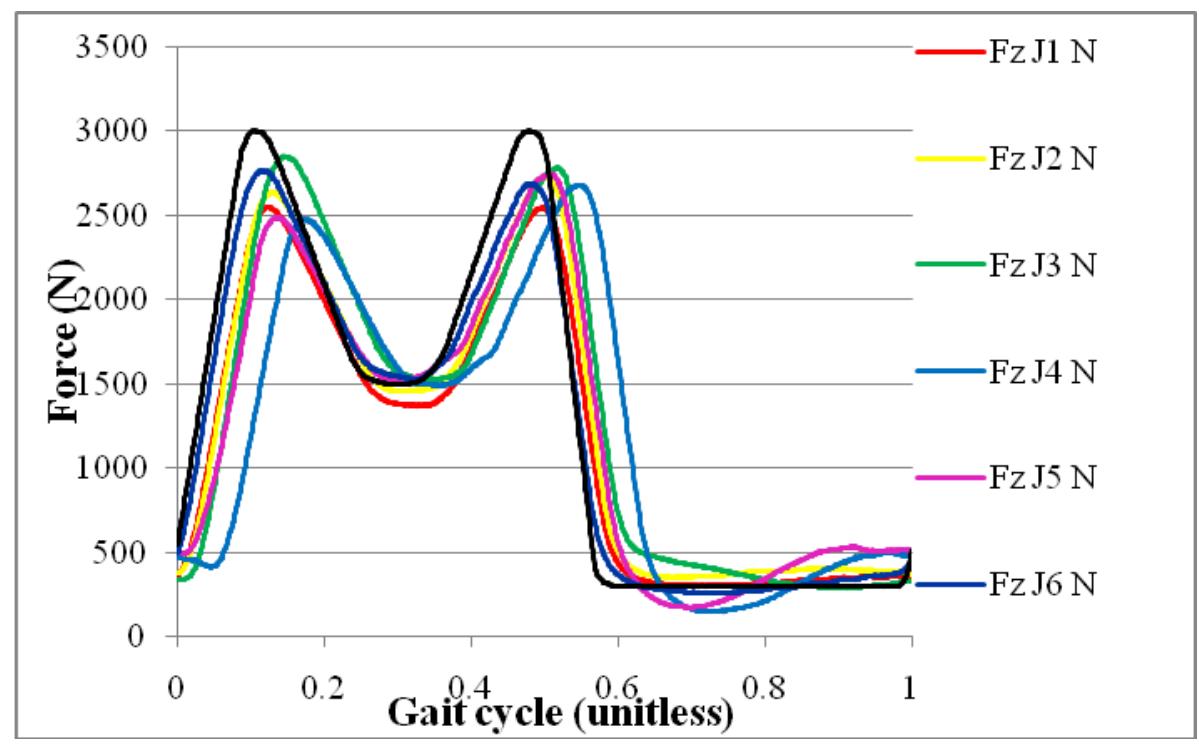

Figure 22 The vertical load input waveform with the vertical output force in the $\mathrm{z}$ direction.

Figure 22shows the input vertical load waveform applied at the implant to be tested (in black) and the output vertical forces at the hip joint in the $\mathrm{z}$ direction in newton while figure 23 shows them in $\% \mathrm{BW}$. The input vertical load waveform represents the ground reaction force if the joint is implanted in a patient and the output vertical forces represent the joint reaction force during walking.

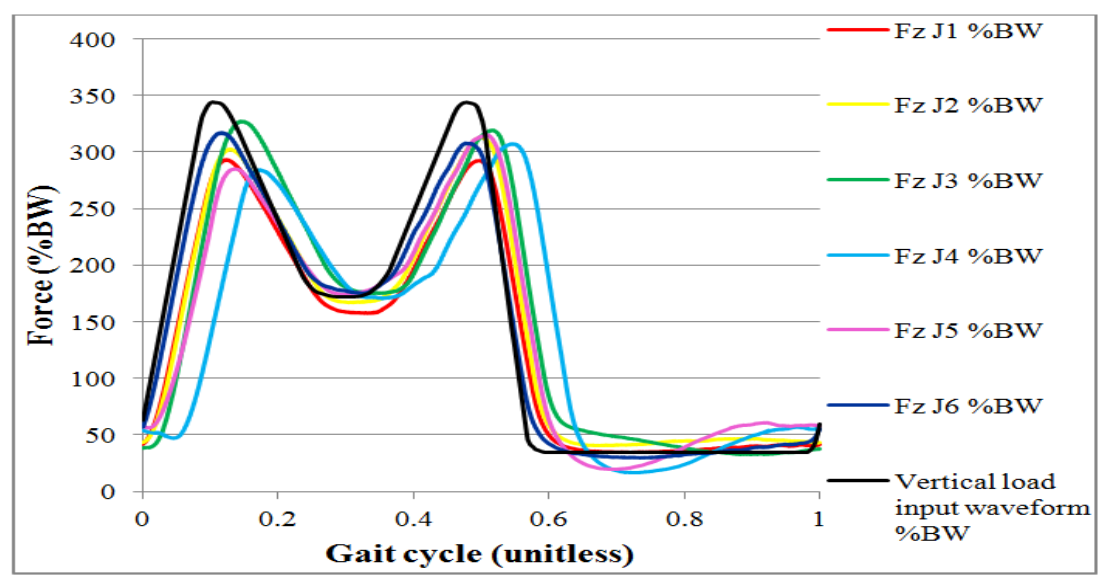

Figure 23 The vertical load input waveform with the vertical output force in the $\mathrm{z}$ direction in $\% \mathrm{BW}$. 


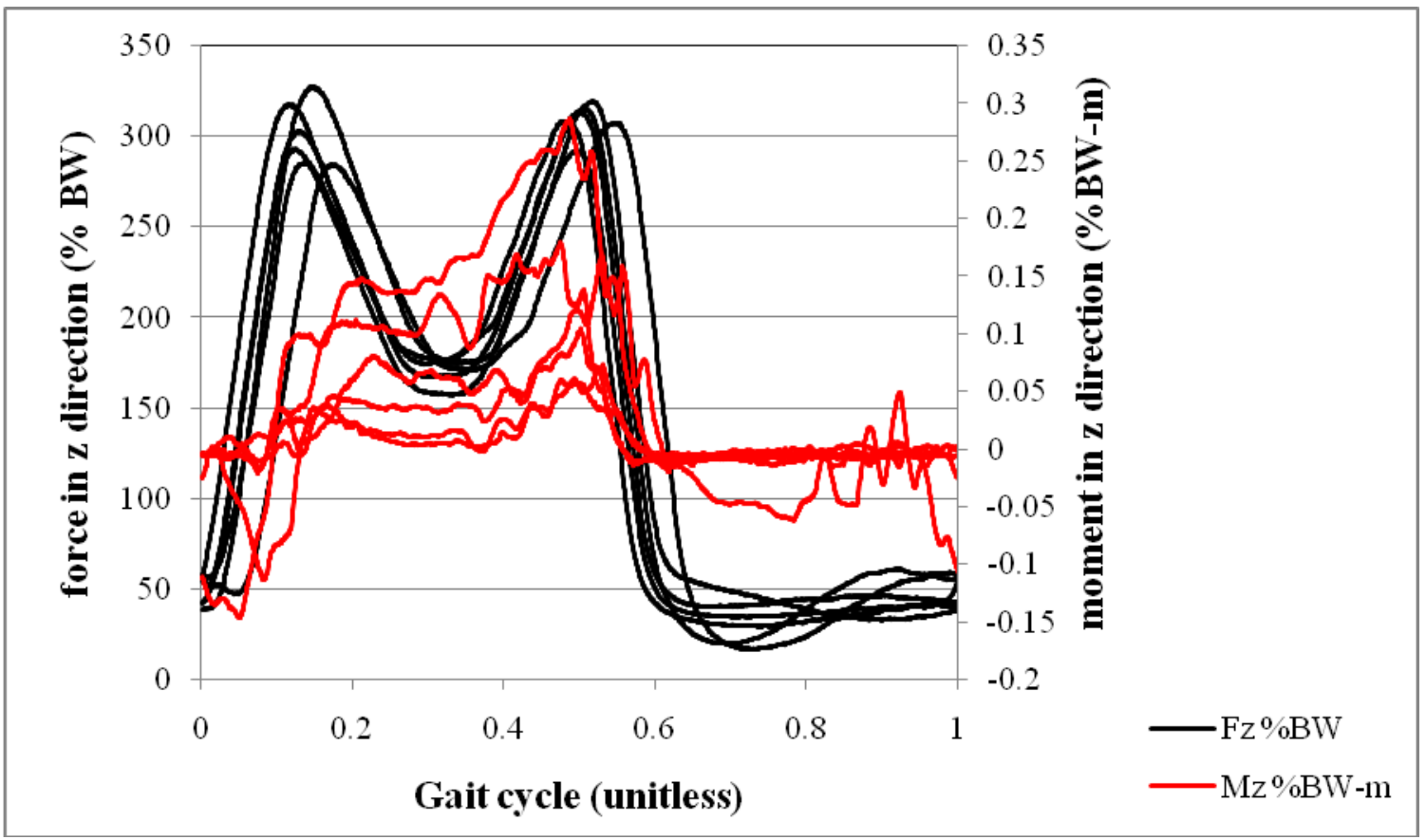

Figure 24 Forces (black) and moments (red) measured at the tested implants in the vertical $\mathrm{z}$ direction in $\% \mathrm{BW}$ and $\% \mathrm{BW}-\mathrm{m}$ respectively.

Figure 24 shows the forces and moments measured at the tested implants in the $\mathrm{z}$ vertical direction, regardless the noise appearing in the moment curves; it's obvious that moments follow the forces' two peaks and generally their shapes reaching zero approximately as the force reaches its steady value.

\section{Discussion and conclusions}

The forces and moments applied at the hip joint implant during one walking gait cycle were displayed in the previous section. Since only six hip implants were tested, no statistical analysis could be performed on the results.

As can be seen, moderate differences in the results were observed between implants one and two which had acetabular cups made of cross-linked polyethylene and the implants three to six which had acetabular cups made of UHMWPE and the forces and moments applied on them were all in the same range; then regarding the forces and moments both materials have the same design properties.

Obviously from Figure 12 the forces in the $\mathrm{x}$ and $\mathrm{y}$ directions are negligible in magnitude compared to the force in the $\mathrm{z}$ direction so it could be assumed that $\mathrm{Fz}$ is the same as the resultant force $\left(\mathrm{F}_{\text {res }}\right)$ that is applied at the hip implant because Fx and Fy have a negligible effect on the magnitude of $F_{\text {res. }}$ The $F_{\text {res }}$ curve, which is the $F z$ curve according to the mentioned assumption, has two peaks with a drop off between them following the shape of the input vertical load waveform as shown in Figure 22 and nearly at the same time with it; this curve shape is similar to the general shape of hip joint force during gait cycle researched by several investigators (Rydell 1966 [8], G. Bergmann et al. 2001 [9], Philip Damm et al. 2015 [10], R. D. Crowninshield et al. [11] and others). Though the maximum peaks are generally greater than that in these research and that's because the muscle forces that pull the joint components close together against the joint force and lessen it do not exist in the simulation of the research testing machine, the testing result do not include the muscles' forces applied at the implant when it is implanted in the human body. The first peak of the resultant force, which is a feature in the general shape of the force applied at the joint, ranges between $2485-2850 \mathrm{~N}(285-327 \% \mathrm{BW})$ at about $15 \%$ of the gait cycle. The second peak which is also a usual feature in the general force shape ranges between 2543$2780 \mathrm{~N}(292-319 \% \mathrm{BW})$ at about $52 \%$ of the gait cycle.

\section{References}

[1]. $\quad$ R. A. Berger, "Leg Extension Force at Three Different Angles.," Research Quarterly. American Association for Health, Physical Education and Recreation, vol. 37, no. 4, pp. 560-562, 1966.

[2]. V. T. INMAN, Human Walking, Baltimore USA: Williams and Wilkins, 1981

[3]. V. T. Inman, "Functional aspects of the abductor muscles of the hip," Journal of Bone and joint surgery, vol. 29, pp. 607-619, 1947.

[4]. L. Zhang, "A Briefing on the Manufacture of Hip Joint Prostheses," Advanced Materials Research, Vols. 76-78, pp. 212-216, 2009.

[5]. M. SCHALDACH, Engineering in medicine 2 : Advances in Artificial Hip and Knee Joint Technology, New York: Springer-Verlag Berlin Heidelberg, 1976.

[6]. AMTI Force 5 manual, 2006 
[7]. Anthropometric Reference Data for Children and Adults $\backslash$ vital and health statistics, 2016.

[8]. N. W. RYDELL, "FORCES ACTING ON THE FEMORAL," Tryckeri AB Litotyp, Goteborg Sweden, 1966.

[9]. G. Bergmann, "Hip contact forces and gait patterns from routine activities," Journal of Biomechanics, no. 34, pp. 859-871, 2001.

[10]. P. Damm, "Postoperative Changes in In Vivo Measured Friction in Total Hip Joint Prosthesis during Walking," PLOS ONE, pp. 1$15,2015$.

[11]. R. D. CROWNINSHIELD, "A BIOMECHANICAL INVESTIGATION OF THE HUMAN HIP," Journal of Biomechanics, vol. 11, pp. $75-85,1978$ 